\title{
A survey of mHealth use from a physician perspective in paediatric emergency care in the UK and Ireland
}

\author{
Haiko Kurt Jahn ${ }^{1,2}$ (1) Ingo Henry Johannes Jahn ${ }^{3} \cdot$ Wilhelm Behringer ${ }^{4} \cdot$ Mark D. Lyttle ${ }^{5,6} \cdot$ Damian Roland ${ }^{7,8} \cdot$ On \\ behalf of Paediatric Emergency Research United Kingdom and Ireland (PERUKI)
}

Received: 8 September 2020 / Revised: 5 March 2021 / Accepted: 10 March 2021 / Published online: 25 March 2021

(C) The Author(s) 2021

\begin{abstract}
There has been a drive towards increased digitalisation in healthcare. The aim was to provide a snapshot of current apps, instant messaging, and smartphone photography use in paediatric emergency care. A web-based self-report questionnaire was performed. Individual physicians working in paediatric emergency care recorded their personal practice. One hundred ninetyeight medical doctors completed the survey. Eight percent of respondents had access to institutional mobile devices to run medical apps. Eighty-six percent of respondents used medical apps on their personal mobile device, with $78 \%$ using Apple iOS devices. Forty-seven percent of respondents used formulary apps daily. Forty-nine percent of respondents had between 1-5 medical apps on their personal mobile device. Respondents who used medical apps had a total of 845 medical apps installed on their personal device, accounted for by 56 specific apps. The British National Formulary (BNF/BNFc) app was installed on the personal mobile device of $96 \%$ of respondents that use medical apps. Forty percent of respondents had patient confidentiality concerns when using medical apps. Thirty-eight percent of respondents have used consumer instant messaging services, $6 \%$ secure specialist messaging services, and 29\% smartphone photography when seeking patient management advice.
\end{abstract}

\section{Conclusion}

App use on the personal mobile devices, in the absence of access to institutional devices, was widespread, especially the use of a national formulary app. Instant messaging and smartphone photography were less common. A strategic decision has to be made to either provide staff with institutional devices or use software solutions to address data governance concerns when using personal devices.

Communicated by Piet Leroy

Haiko Kurt Jahn

haiko.jahn@ doctors.org.uk

Ingo Henry Johannes Jahn

i.jahn@uq.edu.au

Wilhelm Behringer

Wilhelm.Behringer@med.uni-jena.de

Mark D. Lyttle

mdlyttle77@gmail.com

Damian Roland

dr98@leicester.ac.uk

Friedrich-Schiller-Universität Jena, Jena, Thüringen, Germany

2 Children's Emergency Department, Royal Belfast Hospital for Sick Children, 274 Grosvenor Rd, Belfast BT12 6BA, UK
3 School of Mechanical and Mining Engineering, The University of Queensland, Brisbane, QLD 4072, Australia

4 Faculty of Medicine, Center of Emergency Medicine, Friedrich-Schiller-Universität Jena, Jena, Thüringen, Germany

5 Emergency Department, Bristol Royal Hospital for Children, Upper Maudlin Street, Bristol BS2 8BJ, UK

6 Academic Department of Emergency Care, University of the West of England, Blackberry Hill, Avon, Bristol BS16 1DD, UK

7 SAPPHIRE Group, Health Sciences, University of Leicester, Leicester LE1 6TP, UK

8 Children's Emergency Department, Royal Infirmary, Paediatric Emergency Medicine Leicester Academic (PEMLA) Group, Leicester LE1 5WW, UK 
What is Known:

- $m$ Health use by junior doctors and medical students is widespread.

- Clinicians' use of instant messaging apps such as WhatsApp is the widespread in the UK and Ireland, in the absence of alternatives.

What is New:

- Personal mobile device use was widespread in the absence of alternatives, with the British National Formulary nearly universally downloaded to physicians' personal mobile devices.

- A third of respondents used instant messaging and smartphone photography on their personal mobile device when seeking patient management advice from other teams in the absence of alternatives.

Keywords Child health $\cdot$ Emergency medicine $\cdot$ Information science $\cdot$ Health service research $\cdot$ Paediatrics

\section{Introduction}

The invention of mobile devices and apps has resulted in the development of mobile health (mHealth) [1,2]. Coupled with technological advances, and near ubiquitous use of mobile devices in the population, mHealth can be used by both patients and clinicians. There are relatively few reports on its use in each group, and it is important to understand perceptions and use of mHealth from a physician perspective. Apps targeted at physicians have the potential to improve patient care by allowing immediate access to medical and health care information, improving decision making, reducing medical errors, and enhancing telemedicine capabilities [3-6]. The use of mHealth in paediatric emergency care for remote triage and video consultation has been reported $[1,7]$; the use of mHealth in general in response to the COVID 19 pandemic has increased [8-10].

In paediatric emergency care, the use of digital aids to reduce human error, especially in prescribing, has been recognised [11]. Developers have shown apps to be superior in inotrope prescribing compared to using hardcopy formularies, with medical students outperforming specialists [3, 12].

The rapid and organic growth of mHealth technology continually creates new challenges [13] including patient information being exposed to online attacks, concerns regarding confidentiality, lack of quality control, new evidence overtaking available algorithms and guidance, and patient and physician acceptability [7].

The introduction of the European GDPR Regulation in 2018 has mainly focused on ensuring a high level of communication encryption when using email or mobile device technology to ensure confidentiality when patient identifiable information (e.g. images or electronic records) are shared or accessed [14-16]. Serious breaches of patient confidentiality have been reported from the use of personal instant messaging apps, which have led to the development of secure specialist messaging apps for mHealth $[16,17]$; yet despite this, surveys suggest widespread use of consumer-oriented instant messaging apps in healthcare in Europe [18-22].

Strategy and recommendations for institutions on how to manage the necessary digital transformation in healthcare exist for example in the UK, Ireland, Austria and Switzerland $[15,23-26]$. Others such as Germany focussed on creating an electronic patient dossier, containing basic patient data and medication plans that can be accessed by all health providers involved in the patients care [27].

The aim of this survey was to provide a snapshot of current mHealth use from a healthcare provider perspective in paediatric emergency care. We hypothesis if the use of mHealth is of benefit to physicians working in paediatric emergency care, then the use of mHealth will be widespread. Specific examples of this would be if a formulary apps is easier to use than other resources, then physicians would use formulary apps frequently, because they provide near instantaneous information at the bedside. Or if instant messaging and smartphone photography is less cumbersome then departmental camera use for medical photography, then physicians will default to using their personal device, especially if no other alternatives such as institutional mobile devices are provided.

\section{Method}

The online survey was undertaken between 31/07/2017 and 14/01/2018, delivered via SurveyMonkey (www. surveymonkey.com). Survey content was derived by the lead researcher from previous literature examining mobile device and medical app use by clinicians [6, 28, 29], and refined iteratively by an expert panel to ensure content validity and reliability, and piloted. This survey investigated individual physician use of mHealth, i.e. the use of mobile devices and apps to aid patient management as part of a wider study of mHealth use in emergency care (adult and paediatric) in English and German speaking countries in Europe $[13,30,31]$. The survey was distributed via (i) 
Paediatric Emergency Research in the UK and Ireland 45 site leads (PERUKI) [32], a collaborative paediatric emergency research network, which includes mixed (adult and paediatric) and stand-alone paediatric Emergency Departments from urban and rural settings (for further information see https:// www.peruki.org) [32], (ii) the Royal College of Emergency Medicine newsletter and website, and (iii) social media. The link to the survey was shared on the twitter feed of the authors. Respondents accessed the survey via the shared link. Questions included multiple selection and free text answers (Appendix: Survey Questionnaire). Data collected included basic demographic information, mobile device policy, Wi-Fi access, mobile device type, app types, app use, app communication, and percep of app use in clinical practice.

\section{Statistical analysis}

All completed responses were included in the analysis, this included survey responses were respondents skipped individual questions. Partially completed responses were excluded as analysis of these responses showed no noteworthy differences to the completed responses. Microsoft Excel (Version 16.18) was used to undertake descriptive analysis of complete responses. Free text was analysed either for single word answers e.g. name of an app, or the lead author conducted thematic analysis to identify common themes. The thematic analysis followed Braun and Clarke's six phases of thematic analysis [33]. Following familiarisation with the data set, the authors created codes for answers with similar topics such as "smartphone photography". Initial themes were then generated to give meaning to the codes. These themes were then checked against the entire coded data set. Co-authors verified this process. These themes were then analysed.

\section{Ethics}

This survey accessed clinicians via a research collaborative to assess their individual practice and therefore did not require formal ethics review according to the Framework for Health and Social Care Research (UK) [34]. Consent was implied by participation.

\section{Results}

We received 198 complete and 45 incomplete survey responses of physicians involved in resuscitating children and working in paediatric emergency care from the UK and Ireland. Individual physicians from 37 out of the 45 PERUKI sites responded to the survey (supplementary table 1) with a mean of 3 and a median of 2 responses per site, further details regarding site demographic can be found at www.peruki.org. The majority of respondents were consultants and worked at a PERUKI site, and the mean age of respondents was 39 years. Demographics including institutional mobile device, Wi-Fi provision and guidance are listed in Table 1 (supplementary table 1 and 2)

\section{Individual physician app use}

Eighty-nine percent (177/198) of respondents reported using their personal mobile device for web access daily at work. Forty-seven percent (94/198) reported using a formulary app daily on their personal mobile device (Table 2)

One hundred seventy respondents reported using medical apps on their personal mobile device at work. Of these $78 \%$ (132/170) reported using Apple IOS devices and 22\% (38/ 170) Android devices. Of these 1\% (1/170) had 0 medical apps, 55\% (83/170) had 1-5 medical apps, 32\% (54/170) had 6-10 medical apps, and 19\% (32/170) had more than 10 medical apps installed on their personal mobile device.

One hundred sixty-three respondents provided a total of 845 free text responses of the names of the medical apps installed on their personal devices, accounted for by 56 specific apps. The leading app category was "resuscitation" with 170 instances, followed by formulary apps with 157 instances. The $B N F / B N F c$ formulary app $(96 \%, 157 / 163)$ was the only app in this category. This was followed by an antimicrobial guidance app Microguide (42\%,69/163), PaediatricEmergencies (38\%, 63/163), GrowthChart (27\%, $44 / 163)$ and the NeoMate $(25 \%, 40 / 163)$ app (Table 3).

\section{Harm and perception of medical app use}

No respondent reported any adverse events or patient harm from mobile device or medical app use as part of patient care. Seventy-two percent (144/198) of respondents perceived the use of medical apps as a positive development.

Fifty-nine percent (116/198) of respondents selected that they as physicians perceived app use during consultations as acceptable. When asked for their opinion on how their patients perceived app use during consultation, 46\% (91/198) selected acceptable and 46\% (92/198) selected unacceptable, unprofessional or showing lack of knowledge (Table 4). One hundred thirty-eight respondents provided free text responses related to patient comments on medical app use (supplementary table 3 ). Forty-five percent $(89 / 198)$ reported that they received no comments from patients, and stated that this was most likely because they always explained app use to patients prior to use.

There was an almost equal divide amongst respondents in relation to confidentiality concerns when using medical apps; $40 \%$ (79/198) had concerns, 31\% (61/198) had no concerns, and $29 \%(58 / 198)$ were unsure. Sixty-six respondents highlighted their patient confidentiality concerns in additional free text responses (supplementary table 4) 
Table 1 Demographics individual clinician survey

\begin{tabular}{ll}
\hline Question & $\begin{array}{l}\text { Response \% } \\
(n=198)\end{array}$ \\
\hline
\end{tabular}

$\begin{array}{lll}\text { What is your gender? } & & \\ \text { - Male } & 105 & 53 \% \\ \text { • Female } & 93 & 47 \% \\ \text { Could you select your region? } & & \\ \text { - England } & 129 & 65 \% \\ \text { - Northern Ireland } & 27 & 14 \% \\ \text { - Scotland } & 19 & 10 \%, \\ \text { - Wales } & 13 & 7 \%, \\ \text { - Republic of Ireland } & 10 & 5 \%, \\ \text { What is your role? } & & \\ \text { - Consultants (attending physician) } & 103 & 52 \% \\ \text { - Trainee Doctors } & 94 & 47 \% \\ \text { - General Practitioners } & 1 & 1 \%\end{array}$

Are you aware of your institution's mobile device policy?

- Aware of institution's mobile device policy $\quad 101 \quad 51 \%$

Are you provided with an institutional mobile device to run Medical Apps?

- Provided with institutional mobile device $\quad 16 \quad 8 \%$

Do you use Medical Apps on your personal mobile device?

- Use medical apps on personal mobile device $\quad 169 \quad 86 \%$

Wi-Fi access

- Free Wi-Fi access

$122 \quad 62 \%$

- No Wi-Fi access

$63 \quad 32 \%$

- Limited Wi-Fi access (e.g. poor signal strength) patient management advice from colleagues or other specialities (supplementary table 5).

The leading reported reason for using smartphone photography and instant messaging as a communication tool on personal devices was convenience and ease of use $22 \%$ (44/198), followed by a lack of institutional alternatives in 14\% (28/ 198). Six percent (12/198) reported that they only use smartphone photography and instant messaging on institutional devices.

For accessing medical apps (e.g. formulary app) $72 \%$ (142/ 198) preferred personal devices, compared to $10 \%(19 / 198)$ who preferred institutional devices. In contrast, for medical photography institutional devices were preferred by $40 \%$ (78/198), whilst 9\% (18/198) of respondents used these functions on personal devices.

Of respondents using smartphone photography and instant messaging, 29\% (57/198) anonymised patient details as an added security feature (i.e. either no patient identifier or initials only included). A minority did not anonymise photographs $(4 \%, 8 / 198)$ or instant messages $(3 \%, 6 / 198)$ sent from personal devices, citing end-to-end encryption (supplementary table 6)

\section{Barriers and drivers/enablers of app use}

Eighty-five percent (169/198) of respondents reported barriers to medical app use, with the main barrier being the lack of internet or Wi-Fi connection. Ninety-one percent (181/198) of respondents reported enablers and drivers for medical app use, in which time saving and simplification of tasks were most frequently reported (Table 5 and supplementary table 7).

\section{Other}

In $82 \%(162 / 198)$ of respondents, "recommendation by colleagues" was the deciding factor on which apps to install and use (supplementary tables 8). Additional features including
Table 2 Respondents use of personal mobile device

\begin{tabular}{lllllll}
\hline & $\begin{array}{l}\text { Daily } \\
(n=198)\end{array}$ & $\%$ & $\begin{array}{l}\text { Weekly } \\
(n=198)\end{array}$ & $\%$ & $\begin{array}{l}\text { Rarely } \\
(n=198)\end{array}$ & $\%$ \\
\hline - Web access & 177 & $89 \%$ & 6 & $3 \%$ & 9 & $5 \%$ \\
- Calendar, rota & 137 & $69 \%$ & 24 & $12 \%$ & 11 & $6 \%$ \\
- Email access (work email) & 133 & $67 \%$ & 7 & $4 \%$ & 13 & $7 \%$ \\
- Formulary/drug reference & 94 & $47 \%$ & 52 & $26 \%$ & 25 & $13 \%$ \\
- Clinical score/calculator & 55 & $28 \%$ & 58 & $29 \%$ & 51 & $26 \%$ \\
- Education (revision and learning) & 46 & $23 \%$ & 61 & $31 \%$ & 56 & $28 \%$ \\
- Disease diagnosis or management & 33 & $16 \%$ & 56 & $28 \%$ & 70 & $35 \%$ \\
- CPD (Continuing Professional & 15 & $8 \%$ & 75 & $38 \%$ & 52 & $26 \%$ \\
$\quad$ Development), NHS eportfolio etc. & 6 & $3 \%$ & 14 & $7 \%$ & 42 & $21 \%$ \\
\hline
\end{tabular}


Table 3 Apps on the personal mobile device respondents

\begin{tabular}{|c|c|c|c|}
\hline Topic & Name of app & $n=163$ & $\%$ \\
\hline Resuscitation & $\begin{array}{l}\text { - Paediatric Emergencies } \\
\text { - Neomate } \\
\text { - Paeds ED } \\
\text { - Paeds Emergency Tools } \\
\text { - iResus } \\
\text { - PICU calculator } \\
\text { - Mersey burn calculator } \\
\text { - Medical Emergency } \\
\text { - APLS }\end{array}$ & $\begin{array}{l}63 \\
40 \\
21 \\
14 \\
11 \\
11 \\
5 \\
3 \\
2\end{array}$ & $\begin{array}{l}39 \% \\
25 \% \\
13 \% \\
9 \% \\
7 \% \\
7 \% \\
3 \% \\
2 \% \\
1 \%\end{array}$ \\
\hline Formulary & $\cdot \mathrm{BNF}$ & 157 & $96 \%$ \\
\hline Calculator & $\begin{array}{l}\text { - MDCalc } \\
\text { - MedCalx } \\
\text { - MedCalc } \\
\text { - Calculator } \\
\text { - Clinicalc } \\
\text { - grace calculator } \\
\text { - drug dose calculator } \\
\text { - Medical calculator }\end{array}$ & $\begin{array}{l}39 \\
25 \\
19 \\
19 \\
13 \\
10 \\
5 \\
4\end{array}$ & $\begin{array}{l}24 \% \\
15 \% \\
12 \% \\
12 \% \\
8 \% \\
6 \% \\
3 \% \\
2 \%\end{array}$ \\
\hline Reference & $\begin{array}{l}\text { - NICE } \\
\text { - Oxford handbook of clinical } \\
\text { medicine } \\
\text { - Oxford handbook of emergency } \\
\text { medicine } \\
\text { - Uptodate } \\
\text { - BMJ best practice } \\
\text { - RCH Melbourne clinical practical } \\
\text { guidelines } \\
\text { - Medscape } \\
\text { - 3D Brain } \\
\text { - Neonatal Intensive Care } \\
\text { - Patient.co.uk } \\
\text { - Wikipedia } \\
\text { - Ganz } \\
\text { - Traumapedia }\end{array}$ & $\begin{array}{l}17 \\
14 \\
14 \\
14 \\
13 \\
11 \\
\\
9 \\
4 \\
3 \\
3 \\
2 \\
2 \\
2\end{array}$ & $\begin{array}{l}9 \% \\
9 \% \\
8 \% \\
7 \% \\
6 \% \\
2 \% \\
2 \% \\
2 \% \\
1 \% \\
1 \% \\
1 \%\end{array}$ \\
\hline $\begin{array}{c}\text { Disease/task } \\
\text { specific }\end{array}$ & $\begin{array}{l}\text { - Growth Charts } \\
\text { - BiliApp } \\
\text { - POPS } \\
\text { - Med Gas Log } \\
\text { - NICU tools } \\
\text { - PediaBP } \\
\text { - Marispan } \\
\text { - My haemophilia centre }\end{array}$ & $\begin{array}{l}44 \\
18 \\
11 \\
7 \\
7 \\
5 \\
3 \\
1\end{array}$ & $\begin{array}{l}27 \% \\
11 \% \\
7 \% \\
4 \% \\
4 \% \\
3 \% \\
2 \% \\
1 \%\end{array}$ \\
\hline $\begin{array}{l}\text { Anti-microbial } \\
\text { Guidance }\end{array}$ & $\begin{array}{l}\text { - Microguide } \\
\text { - Alderhey antibiotic guidelines } \\
\text { - Mersey antibiotic guidelines }\end{array}$ & $\begin{array}{l}69 \\
11 \\
4\end{array}$ & $\begin{array}{l}42 \% \\
7 \% \\
2 \%\end{array}$ \\
\hline Local/ Institutional & $\begin{array}{l}\text { - Induction } \\
\cdot \text { HANDi app } \\
\text { - HEFT EMapp } \\
\text { - NCHD.ie } \\
\text { - RBHSC app } \\
\text { - RLEMH } \\
\text { - EMed.ie }\end{array}$ & $\begin{array}{l}20 \\
8 \\
6 \\
5 \\
5 \\
2 \\
1\end{array}$ & $\begin{array}{l}12 \% \\
5 \% \\
4 \% \\
3 \% \\
3 \% \\
1 \% \\
1 \%\end{array}$ \\
\hline Education & $\begin{array}{l}\text { - SimMon } \\
\text { - EM:RAP } \\
\text { - BMJ OneExamination } \\
\text { - SCCM } \\
\text { - RCEM learning }\end{array}$ & $\begin{array}{l}10 \\
6 \\
5 \\
4 \\
3\end{array}$ & $\begin{array}{l}6 \% \\
4 \% \\
3 \% \\
2 \% \\
2 \%\end{array}$ \\
\hline
\end{tabular}

Table 3 (continued)

\begin{tabular}{llll}
\hline Topic & Name of app & $n=163$ & $\%$ \\
\hline & $\bullet$ kaizen/eportfolio & 3 & $2 \%$ \\
& $\cdot$ RCPCH CPD & 2 & $1 \%$ \\
& $\cdot$ foam (free open access medical & 2 & $1 \%$ \\
& $\quad$ education) & & \\
Communication & - mobileiron & 14 & $9 \%$ \\
\hline
\end{tabular}

perceived medical app accuracy and safety (supplementary table 9), app design experience (supplementary table 10), most useful medical app features (supplementary table 11), and themes for future app development (supplementary table 12) are listed in the supplementary tables.

\section{Discussion}

This survey investigated mHealth use from a physician perspective in paediatric emergency care. The use of apps by individual physicians on their personal mobile devices in the absence of institutional devices was widespread. Nearly half of respondents reported using a formulary app daily, whereas instant messaging use was use by a third. The use of mobile devices and apps as part of patient management was generally well perceived by physicians.

\section{General considerations}

The survey provided data from a large sample across a range of Emergency Department types, regions and subgroups of physicians involved in paediatric emergency care and the resuscitation of children. Respondents were nearly equally split between consultants and trainees. Whilst high use of mobile device technology as part of patient care has previously been reported from doctors in training $[6,28,35]$, this study provides a more accurate overall reflection of reported use.

The provision of institutional mobile devices was low, forcing staff to default to personal devices, independent of whether they agree to this or not. Respondents showed a clear preference for institutional mobile devices for patient identifiable data such as smartphone photography, similar to existing literature [28, 36, 37]. Personal mobile devices were preferred for accessing medical apps (e.g. reference, formulary apps) for functions that did not require patient identifiable information [37].

Moving forward mobile device use policy and guidance needs to reflect this reality of widespread personal mobile device use in the clinical environment that has previously been reported [28, 37-39], in the absence of institutional devices. 
Table 4 Perception of app use

\begin{tabular}{|c|c|c|c|c|}
\hline & $\begin{array}{l}\text { Perception: } \\
\text { Unprofessional, rude, shows lack of } \\
\text { knowledge } \\
(n=198, \%)\end{array}$ & $\begin{array}{l}\text { Perception: } \\
\text { Acceptable } \\
(n=198, \%)\end{array}$ & $\begin{array}{l}\text { Perception: } \\
\text { Professional } \\
(n=198, \%)\end{array}$ & $\begin{array}{l}\text { Other } \\
(n=198, \%)\end{array}$ \\
\hline Physician perception of medical app use & $44,22 \%$ & $116,59 \%$ & $28,14 \%$ & $10,5 \%$ \\
\hline Analysis of responses & $\begin{array}{l}33 \text { unprofessional } \\
8 \text { rude } \\
3 \text { shows lack of knowledge }\end{array}$ & $\begin{array}{l}84 \text { acceptable } \\
32 \text { acceptable if } \\
\text { explained }\end{array}$ & $\begin{array}{l}28 \\
\text { profes- } \\
\text { sional }\end{array}$ & $\begin{array}{l}7 \text { not in front of } \\
\text { patients } \\
3 \text { mixed }\end{array}$ \\
\hline $\begin{array}{l}\text { Patient and carer perception of medical app use from } \\
\text { physicians' perspective }\end{array}$ & $91,46 \%$ & $92,46 \%$ & $4,2 \%$ & $11,6 \%$ \\
\hline Analysis of responses & $\begin{array}{l}44 \text { unprofessional } \\
34 \text { shows lack of knowledge } \\
13 \text { rude }\end{array}$ & $\begin{array}{l}64 \text { acceptable } \\
28 \text { acceptable if } \\
\text { explained }\end{array}$ & $\begin{array}{l}\text { profes- } \\
\text { sional }\end{array}$ & $\begin{array}{l}9 \text { mixed } \\
2 \text { unsure }\end{array}$ \\
\hline
\end{tabular}

Personal mobile devices may actually be a low-cost solution to improve and revolutionise healthcare [37].

Respondents reported variability in provisioned $\mathrm{Wi}-\mathrm{Fi}$, with lack of Wi-Fi reported as a barrier to app use. Infrastructure provision such as free Wi-Fi and apps are key to support this advance in technology in healthcare $[9,10$, 39-42].

There has been a lack of patient involvement in the development of digital strategies. In 2014 the iDoc project which provided junior doctors with medical apps on their mobile devices explored potential perceptions of apps. They proposed that app use at the bedside might be perceived as "using social media and playing games" or that patients "can see it negatively at the bedside" [28, 43, 44]. Physicians in our survey reported mHealth in general as an acceptable development, as previously reported [21]. In the experience and opinion of respondents to our survey, patients may perceive this use as acceptable as well. This opinion appears to be strengthened by taking the step of explaining mobile device use to patients. Similarly respondents reported consenting patients to smartphone photography and taking written consent for patient identifiable areas such as the face, reflecting guidance from the British Association of Dermatologists [45]. Our results support this pragmatic inclusive approach as part of good digital practice

\section{Medical apps}

Half of our respondents used formulary apps, and one-third used medical calculator or clinical score apps daily. The single leading app was the $B N F / B N F c$ formulary app; this app has consistently been chosen as the most popular and widely used medical app in the UK. Reported reasons include ease of use, ready access, access to standardised national guidance, and frequent updates $[43,46]$. Others may wish to develop their own version of a free national formulary apps based on the
Table 5 Reported barriers and drivers/enablers of medical app use

\begin{tabular}{lllll}
\hline & $\begin{array}{l}\text { Barrier } \\
(n=169)\end{array}$ & $\%$ & $\begin{array}{l}\text { Driver/Enabler } \\
(n=181)\end{array}$ & $\%$ \\
\hline - Colleagues & 19 & $11 \%$ & 65 & $36 \%$ \\
- Institution & 19 & $11 \%$ & 31 & $17 \%$ \\
- Patients & 15 & $9 \%$ & 7 & $4 \%$ \\
- Technical Issues & 60 & $36 \%$ & 17 & $9 \%$ \\
- Internet or Wi-Fi Connection to run Medical & 101 & $60 \%$, & 64 & $35 \%$ \\
$\quad$ App & 58 & 101 & & $34 \%$ \\
- Price* & 11 & $7 \%$ & 109 & $60 \%$ \\
- Time** & 7 & $4 \%$ & 90 & $50 \%$ \\
- Helpful*** & 26 & $15 \%$ & 11 & $6 \%$ \\
\hline
\end{tabular}

*Price: barrier: high purchase cost; driver/enabler: free to download

**Time: barrier: prolongs task, driver/enabler: time saving

***Helpful: barrier: complicates task; driver/enabler: simplifies task 
UK experience. This approach may also serve as a blueprint when developing future medical apps.

The two leading resuscitation apps were PaediatricEmergencies [11] and NeoMate [47]. Developers have shown the superiority of apps in paediatric prescribing and burns management compared to paper-based resources $[3,5,12]$.

Regulators classify apps as medical devices if they calculate medicine doses, diagnose disease, or provide a risk score [48, 49]. Clinicians currently using apps that perform these functions without regulatory approval need to be aware of the patient safety implications [48-51]. Regulatory approval can reassure both clinicians and patients, yet only two apps (Mersey Burns and NeoMate) reported in this survey are licensed [5]. In the UK potential issues can be reported to the regulator via the yellow card scheme (https://yellowcard.mhra.gov.uk/).

\section{Communication}

Instant messaging use in healthcare is widespread in the UK and Ireland [38]. Convenience and ease of use in the absence of alternatives were the main reported driver. Respondents defaulted to consumer instant messaging apps despite being aware of security concerns [24, 38, 41, 42], as has been reported from other European countries [18-21, 52]. The NHS instant messaging guidance is based on the European GDPR Regulation [14-16] which recommends the use GDPR compliant secure messaging apps with AES 256 encryption. If these are not available, consumer instant messaging platforms can be used [34, 39].

The National Cyber Security Centre guidance recommends not allowing anyone else to use mobile device used for patient management, setting the device to lock out when not being used and requiring a passcode immediately, disabling message notifications on the device's lock-screen, and enabling remote-wipe in case loss or theft [39, 45], e.g. by registering the device with the NHS BYOD scheme [42]. Other countries have developed similar approaches [24-26].

Some hospitals have banned instant messaging apps wholesale because of security and data governance concerns [38]. This is unlikely to be a long-term solution, and is difficult to enforce given advances in technology, absence of alternatives, and human behaviour [38]. However since the release of this survey, the National Trauma Network in the UK has approved WhatsApp as an official communications app in line with NHS Digital guidance [42, 53]. In this setting the use of WhatsApp revolves around team communication and team management in major incidents, rather than transmitting confidential patient information.

The breach of data protection policies when using messaging apps was raised as the leading data governance concern in our survey. This mainly concerned the sending and sharing of patient details and patient identifiable information e.g. images of ECGs or fractures and the subsequent storage of these on both the sender's and the receiver's device. This risk is

\section{Emergent Themes}

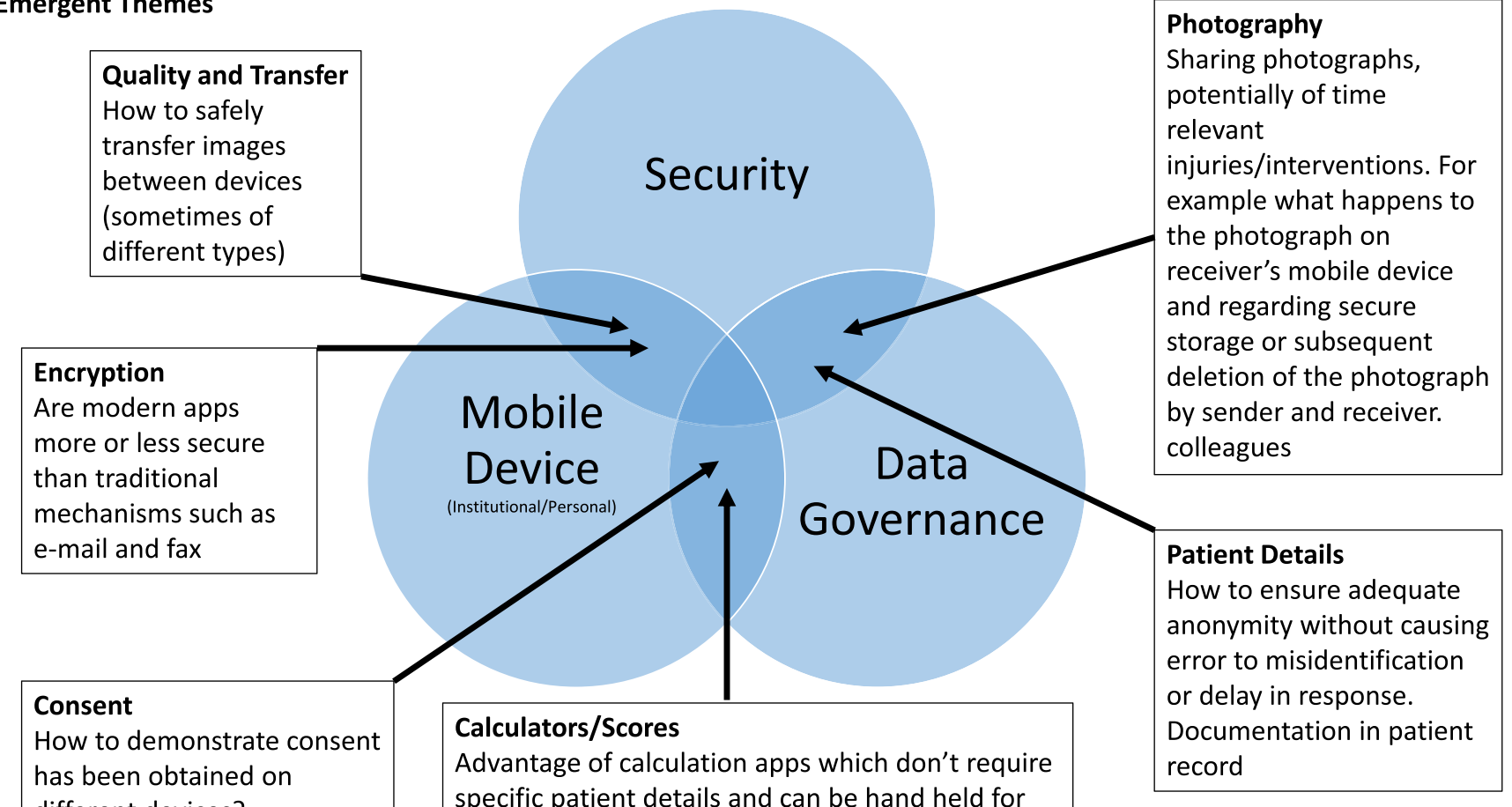

Fig. 1 Emergent themes: Security, data governance and device type 
increased if patient images are held on a personal device, even if anonymised, with an incumbent responsibility to delete any clinical images in an appropriate timeframe [38].

Respondents were especially concerned with data governance once send to other mobile devices. The presence of historic images with patient details on colleagues' personal mobile devices was reported. One way to address this is the use of specialist secure communications app where images are not stored on the device, but on a secure server, such as Siilo, MDSAS, Hospify, Forward and MedxNote, used in the NHS $[54,55]$.

In summary, staff have identified advantages in using mHealth. The use of personal devices is widespread. Concerns have been raised regarding data governance, especially when using instant messaging apps and smartphone photography, which can summarised in three key themes: security (data and device), data governance and device (personal versus institutional mobile device) (Fig. 1). Currently staff have found their own solutions to this issue, i.e. shared decision making with patients when using mobile device technology as part of consultation. Despite the existence of software solution to address these concerns such as secure messaging apps $[54,55]$ and registering the personal device with the NHS BYOD scheme [42], these are not widely adopted. Guidance needs to address this, so that staff can take advantage of the benefits of mHealth when using personals mobile device at work.

\section{Limitations}

The survey was distributed through different channels including personal contact, colleges and societies, and social media; it is therefore impossible to calculate a response rate. Responses may have been influenced by self-selection of the respondents, the availability and support for certain devices and apps. The survey provided data across a range of emergency department types providing paediatric emergency care in the UK and Ireland and from a wide geographic spread across the UK and Ireland. This reduces the risk of bias, with results more likely to reflect a true snapshot of current practice.

\section{Conclusion}

App use on the personal mobile devices, in the absence of access to institutional devices, was widespread, especially the use of a national formulary app. Instant messaging and smartphone photography were less common. Staff have adopted a pragmatic inclusive approach to data governance. Guidance needs to keep pace with this rapidly evolving technology. A strategic decision has to be made to either provide staff with institutional devices or use software solutions to address data governance concerns when using the personal device.

Supplementary Information The online version contains supplementary material available at https://doi.org/10.1007/s00431-021-04023-0.

Acknowledgements Robin Marlow and Vanessa Libal for review of the questionnaire

The following individuals acted as leads for the mobile device app project at their site:

Roger Alcock, Forth Valley Royal Hospital

Mark Anderson, Great North Children's Hospital, Newcastle

Andrew Appelboam, Royal Devon and Exeter Hospital

Michael Barrett, Our Lady's Children's Hospital

Roisin Begley, North Middlesex Hospital

Terri Bentley, Royal United Hospital

Turlough Bolger, Tallaght Children's Hospital

Nanette Bothma, Derriford Hospital

Fiona Bowles, Queen Alexandra Hospital

Adrian Boyle, Cambridge

Adam Brown, Frenchay Hospital

Craig Brown, Aberdeen Royal Infirmary

Jen Browning, Royal Hospital for Sick Children - Edinburgh

Derek Burke, Sheffield Children's Hospital

Nabila Burney, Chelsea \& Westminster Hospital

Fleur Cantle, King's College Hospital

Kirsty Challen, Royal Preston Hospital

John Criddle, Evelina Children's Hospital

Sharryn Gardner, Ormskirk

Eleanor Glenday, St Richard's Hospital, Chichester

Sylvester Gomes, St Richard's Hospital, Chichester

Chris Gough, Nottingham Children's Hospital

Saqib Hasan, Royal Hospital for Sick Children - Glasgow

Lisa Kehler, Royal Wolverhampton

Mike Linney, St Richard's Hospital, Chichester

Dan Magnus, Bristol Royal Hospital for Children

Julie-Ann Maney, Royal Belfast Hospital for Sick Children

Christopher McKie, Sunderland Royal Hospital

Shrouk Messahel, Alder Hey Children's Hospital

Ruud Nijman, St Mary's Hospital

Maggie Nyirenda, Lewisham Hospital

Ronan O'Sullivan, Cork University Hospital

Ami Parikh Barts \& The London

Katherine Potier, Royal Manchester Children's Hospital

Colin Powell, Children's Hospital for Wales

Marimuthu Rajeshkumar, Darlington Memorial Hospital

Darren Ranasinghe, University Hospital Southampton

Gisela Robinson, Royal Derby Hospital

Damian Roland, Leicester Royal Infirmary

Alex Scott, James Cook University Hospital, Middlesbrough

Augustine Smithies, Hull Royal Infirmary

Clare Thompson, Leeds General Infirmary

Emily Walton, Royal Alexandra Children's Hospital

Shye-Wei Wong, Royal Free Hospital

Authors' contributions HKJ: initial Idea, questionnaire, data analysis, manuscript

IHJJ: data analysis, statistics, review

WB: questionnaire, data analysis, review

ML: questionnaire, data analysis, review

DR: questionnaire, data analysis, figure, review

Funding Open Access funding enabled and organized by Projekt DEAL. 


\section{Declarations}

Ethics approval This survey accessed clinicians via a research collaborative to assess their individual practice and therefore did not require formal ethics review according to the Framework for Health and Social Care Research (UK).

Consent to participate Consent was implied by participation

\section{Consent for publication N/A}

Conflict of interest The authors declare no competing interests.

Open Access This article is licensed under a Creative Commons Attribution 4.0 International License, which permits use, sharing, adaptation, distribution and reproduction in any medium or format, as long as you give appropriate credit to the original author(s) and the source, provide a link to the Creative Commons licence, and indicate if changes were made. The images or other third party material in this article are included in the article's Creative Commons licence, unless indicated otherwise in a credit line to the material. If material is not included in the article's Creative Commons licence and your intended use is not permitted by statutory regulation or exceeds the permitted use, you will need to obtain permission directly from the copyright holder. To view a copy of this licence, visit http://creativecommons.org/licenses/by/4.0/.

\section{References}

1. Nevet A, Bitton Y, Wolf L, Waisman Y (2016) Telemedicine: a novel service in pediatric emergency care. Harefuah. 155(7):410413

2. WHO (2011) mHealth: New horizons for health through mobile technologies: second global survey on eHealth. In: Kay M, Santos J, Takane M (eds) WHO

3. Flannigan C, McAloon J (2011) Students prescribing emergency drug infusion utilising smartphones outperforms consultants using BNFCs. Resuscitation. 82:1424-1427

4. STRS (2019) Paediatric Emergency Tools https://apps.apple.com: South Thames Retrieval Service; [Version 5:[Available from: https://www.guysandstthomas.nhs.uk/news-and-events/downloadour-apps.aspx\#na. Accessed 15 July 2018

5. Barnes J, Duffy A, Hamnett N, McPhail J, Seaton C, Shokrollahi K, James MI, McArthur P, Pritchard Jones R (2015) The Mersey Burns App: evolving a model of validation. Emerg Med J. 32(8): 637-641

6. Sayedalamin Z, Alshuaibi A, Almutairi O, Baghaffar M, Jameel T, Baig M (2016) Utilization of smart phones related medical applications among medical students at King Abdulaziz University, Jeddah: a cross-sectional study. J Infect Public Health. 9:691-697

7. Haimi M, Brammli-Greenberg S, Waisman Y, Baron-Epel O (2018) Physicians' experiences, attitudes and challenges in a Pediatric Telemedicine Service. Pediatr Res. 84(5):650-656

8. Bini SA, Schilling PL, Patel SP, Kalore NV, Ast MP, Maratt JD, Schuett DJ, Lawrie CM, Chung CC, Steele GD (2020) Digital orthopaedics: a glimpse into the future in the midst of a pandemic. J Arthroplasty. 35(7S):S68-S73

9. Budd J, Miller BS, Manning EM, Lampos V, Zhuang M, Edelstein M, Rees G, Emery VC, Stevens MM, Keegan N, Short MJ, Pillay D, Manley E, Cox IJ, Heymann D, Johnson AM, McKendry RA (2020) Digital technologies in the public-health response to COVID-19. Nat Med. 26:1183-1192
10. Anthony B Jr (2020) Use of telemedicine and virtual care for remote treatment in response to COVID-19 pandemic. J Med Syst 44(7):132

11. Flannigan C, Flannigan S (2018) Paediatric Emergencies Apple App Store: ITDCS; [updated 15 Jul 2018. Version 1.20: [Available from: https://itunes.apple.com/au/app/paediatricemergencies/id494905887

12. Siebert JN, Ehrler F, Combescure C, Lovis C, Haddad K, Hugon F, Luterbacher F, Lacroix L, Gervaix A, Manzano S, Gehri M, Yersin C, Garcia D, Hermann Marina F, Pharisa C, Spannaus M, Racine L, Laubscher B, Vah C, Llor J, Juzan A (2019) A mobile device application to reduce medication errors and time to drug delivery during simulated paediatric cardiopulmonary resuscitation: a multicentre, randomised, controlled, crossover trial. Lancet Child Adolesc Health. 3(5):303-311

13. Jahn HK, Jahn IH, Roland D, Lyttle MD, Behringer W (2019) Mobile device and app use in paediatric emergency care: a survey of departmental practice in the UK and Ireland. Arch Dis Child. 104:1203-1207

14. Moran C Whats App. 16 February 2018

15. Digital N. Information governance and technology resources [Available from: https://digital.nhs.uk/data-and-information/ looking-after-information/data-security-and-informationgovernance/information-governance-alliance-iga/informationgovernance-resources/information-governance-and-technologyresources. Accessed 15 July 2018

16. T L. WhatsApp use in the NHS a "privacy and clinical safety timebomb'. Mobi Health News; April 03, 2019.

17. M M. Facebook Messenger, WhatsApp, iMessage use at UK NHS adds new security concerns. Mobi News Health; August 30, 2018.

18. $\mathrm{C} M(2018)$ Instant messaging in the NHS: an exploration of the relationship between consumer messaging applications and modern healthcare delivery.: Common Time

19. O'Sullivan DM, et al (2017) WhatsApp Doc? BMJ Innovations

20. Gould G, Nilforooshan R (2016) WhatsApp Doc? BMJ Innov. 2(3):109-110

21. Alexander SM, Nerminathan A, Harrison A, Phelps M, Scott KM (2015) Prejudices and perceptions: patient acceptance of mobile technology use in health care. Intern Med J. 45(11):1179-1181

22. WhatsApp für Ärzte dienstlich ab sofort tabu (2018) Aerzte Zeitung online: Springer Medizin

23. Digital N. NHS Wifif [Available from: https://digital.nhs.uk/ services/nhs-wifi. Accessed 15 July 2018

24. Ireland e. ehealthireland http://www.ehealthireland.ie: eHealth Ireland; 2015 [Available from: http://www.ehealthireland.ie/ Strategic-Programmes/. Accessed 15 July 2018

25. Kohler C, Egger O, Smock M (2018) Mobile Health und das elektronische Patientendossier. eHealth Suisse, Kompetenz - und Koordinationsstelle von Bund und Kan- tonen

26. Kraus - Füreder H (2018) esundheits - Apps. Grundlagenpapier unter besonderer Berücksichtigung des Aspekts Gesundheitskompetenz. Institut für Gesundheits förderung und Prävention. Graz; 13. 03

27. Bundesaerztekammer. E-Health-Gesetz 2016 [Available from: https://www.bundesaerztekammer.de/aerzte/telematiktelemedizin/ earztausweis/e-health-gesetz/. Accessed 15 July 2018

28. Payne KFB, Wharrad H, Watts K (2012) Smartphone and medical related App use among medical students and junior doctors in the United Kingdom (UK): a regional survey. BMC Medical Informatics and Decision Making. 12(1):121

29. Hussain M, Al-Haiqi A, Zaidan AA, Zaidan BB, Kiah ML, Anuar NB et al (2015) The landscape of research on smartphone medical apps: coherent taxonomy, motivations, open challenges and recommendations. Comput Methods Programs Biomed. 122(3):393-408

30. Jahn HK, Jahn IHJ, Roland D, Behringer W, Lyttle M (2020) Paediatric emergency research in the United Kingdom IeP. 
Prescribing in a paediatric emergency: a PERUKI survey of prescribing and resuscitation aids. Acta Paediatr

31. Jahn H (2020) Survey of mobile device and Medical App use in emergency care. In: Digitale Bibliothek Thüringen. FriedrichSchiller University, Jena

32. Lyttle MD, O'Sullivan R, Hartshorn S, Bevan C, Cleugh F, Maconochie I et al (2014) Paediatric Emergency Research in the UK and Ireland (PERUKI): developing a collaborative for multicentre research. Arch Dis Child. 99(6):602-603

33. Braun V, Clarke V (2019) Handbook of research methods in health social sciences. Thematic analysis. Springer, Hoboken, New Jersey

34. HRA. Framework health social care research 2018 [Framework for Health and Social Care Research in the UK]. Available from: https:/www.hra.nhs.uk/planning-and-improving-research/policiesstandards-legislation/uk-policy-framework-health-social-careresearch/. Accessed 15 Jul 2018

35. Carey E, Payne KF, Ahmed N, Goodson A (2015) The benefit of the smartphone in oral and maxillofacial surgery: smartphone use among maxillofacial surgery trainees and iPhone apps for the maxillofacial surgeon. J Maxillofac Oral Surg. 14(2):131-137

36. Andrawis JP, Muzykewicz DA, Franko OI (2016) Mobile device trends in orthopedic surgery: rapid change and future implications. Orthopedics. 39(1):e51-e56

37. Patel RK, Sayers AE, Patrick NL, Hughes K, Armitage J, Hunter IA (2015) A UK perspective on smartphone use amongst doctors within the surgical profession. Ann Med Surg (Lond). 4(2):107-112

38. Martin C (2018) Instant messaging in the NHS: an exploration of the relationship between consumer messaging applications and modern healthcare delivery.: Common Time; [Available from: https:/www.commontime.com/uploads/webpage-documents/ bdbb33eb-d290-4c35-9d90-182edacf317a.pdf

39. Mistry K Information governance considerations for staff on the use of instant messaging software in acute clinical settings: NHS England Publications; 2018 [updated 9 November 2018. Available from: https://digital.nhs.uk/data-and-information/ looking-after-information/data-security-and-informationgovernance/information-governance-alliance-iga/informationgovernance-resources/information-governance-and-technologyresources. Accessed 15 July 2018

40. Manning K, Williams A (2015) Information and technology for better care Health and Social Care Information Centre Strategy 2015-2020: Health and Social Care Information Centre Strategy; [Available from: https://digital.nhs.uk/binaries/content/assets/ legacy/pdf/c/c/hscic-strategy-2015-2020-final-310315.pdf. Accessed 15 July 2018

41. NHS. NHS Wi-Fi NHS Digital: NHS Digital; 2018 [Available from: https://digital.nhs.uk/services/nhs-wifi. Accessed 15 July 2018

42. NHS. Information governance and technology resources https:// digital.nhs.uk: NHS Digital; 2020 [updated 9 April 2020. Available from: https://digital.nhs.uk/data-and-information/ looking-after-information/data-security-and-informationgovernance/information-governance-alliance-iga/information- governance-resources/information-governance-and-technologyresources. Accessed 15 July 2018

43. Hardyman W, Bullock A, Carter-Ingram S, Pugsley L, Stacey M. eLearning in Health Conference: collaboration, sharing and sustainability in the current environment https://www.cardiff.ac.uk: University of Aston; 2011 [Available from: https://www.cardiff. ac.uk/curemede/research/past-projects/idoc. Accessed 15 July 2018

44. Wiechmann W, Kwan D, Bokarius A, Toohey SL (2016) There's an app for that? Highlighting the difficulty in finding clinically relevant smartphone applications. West J Emerg Med. 17(2):191194

45. Schofield J (2017) UK Guidance on the use of mobile photographic devices in dermatology https://www.bad.org.uk: British Association of Dermatologists; [Available from: http://www.bad. org.uk/shared/get-file. ashx ?itemtype $=$ document $\&$ id $=5818$. Accessed 15 July 2018

46. Haffey F, Brady RR, Maxwell S (2014) Smartphone apps to support hospital prescribing and pharmacology education: a review of current provision. Br J Clin Pharmacol. 77(1):31-38

47. Kelly C (2017) NeoMate appstore.com: NTS Neonatal Transfer Service London; [3.1.2:[Neonatal Resuscitation App]. Available from: https://apps.apple.com/gb/app/neomate-for-nicu-staff/ id944319462. Accessed 15 July 2018

48. MHRA. Medical devices regulation and safety: https://www.gov. uk; 2018 [Available from: https://www.gov.uk/topic/medicinesmedical-devices-blood/medical-devices-regulation-safety. Accessed 15 July 2018

49. Bates DW, Landman A, Levine DM (2018) Health apps and health policy: what is needed? JAMA. 320(19):1975-1976

50. Shuren J, Patel B, Gottlieb S (2018) FDA regulation of mobile medical apps. JAMA. 320(4):337-338

51. Lee TT, Kesselheim AS (2018) U.S. Food and Drug Administration precertification pilot program for digital health software: weighing the benefits and risks. Ann Intern Med. 168(10):730-732

52. Winnat C (2018) WhatsApp für Ärzte dienstlich ab sofort tabu. Aerzte Zeitung online: Springer Medizin

53. Moran C (2018) Email: WhatsApp Clinical Groups, National Trauma Network. National Trauma Network

54. Lovell T (2019) WhatsApp use in the NHS a 'privacy and clinical safety timebomb': Mobi Health News; [updated April 03, 2019]. Available from: https://www.mobihealthnews.com/content/ whatsapp-use-nhs-\% E2\% $80 \% 98$ privacy-and-clinical-safetytimebomb\%E2\%80\%99. Accessed 15 July 2018

55. Miliard M (2018) Facebook Messenger, WhatsApp, iMessage use at UK NHS adds new security concerns: Mobi News Health; [updated August 30, 2018]. Available from: https://www. mobihealthnews.com/content/facebook-messenger-whatsappimessage-use-uk-nhs-adds-new-security-concerns. Accessed 15 July 2018

Publisher's note Springer Nature remains neutral with regard to jurisdictional claims in published maps and institutional affiliations. 